\title{
The Study of Phosphate Release from Artificial Sediment into Water Body Using Diffusive Gradient in Thin Film (DGT) Device in Oxic Condition
}

\author{
Ardina Purnama Tirta ${ }^{1, *}$, Asep Saefumillah ${ }^{2}$, Foliatini $^{1}$, and Herawati ${ }^{1}$ \\ ${ }^{1}$ Department of Analytical Chemistry, Polytechnic AKA Bogor, \\ Jl. Pangeran Sogiri No. 283, Tanah Baru, Bogor 16154, West Java, Indonesia \\ ${ }^{2}$ Department of Chemistry, Faculty of Mathematics and Natural Sciences, Universitas Indonesia, Depok Campus, \\ Depok 16424, Indonesia
}

* Corresponding author:

tel: $+62-8176565490$

email:ana.ardina@gmail.com

Received: February 8, 2019

Accepted: July 29, 2019

DOI: $10.22146 /$ ijc. 43482

\begin{abstract}
The phenomenon of phosphate release in sediments into water bodies under oxic environment has been investigated using the Diffusive Gradient in Thin Film (DGT) technique. This research consists of several stages: polymer synthesis and DGT probe assembly, sediment sampling, DGT deployment in oxic conditions, and phosphate analysis from DGT adsorption results. Acrylamide polymer was successfully synthesized with a composition of $15 \%$ acrylamide; $N$-N'-methylenebisacrylamide $0.1 \%$ and ferrihydrite as binding gels. DGT probes were assembled by placing a $16 \times 3.2 \mathrm{~cm}$ polyacrylamide gel, binding gels and filter membranes on the DGT probes. The sediment sample was taken from the Bogor Botanical Gardens at the coordinates 6 $36^{\prime} 00.6^{\prime \prime}$ S; $106^{\circ} 47^{\prime} 51.0^{\prime \prime}$. The DGT probe was placed in sediment samples for 1, 3 and 7 days in oxic conditions. After the prescribed time, the binding gel was removed and cut every $1 \mathrm{~cm}$ depth, then eluted using $0.25 \mathrm{M} \mathrm{H}_{2} \mathrm{SO}_{4}$ and the phosphate concentration was measured using spectrophotometry method. The results showed that the phosphate concentration tends to be higher with the increasing incubation time and depth. Maximum $C_{D G T}$ phosphate released on day 1, day 3 and day 7 were $1.00 \mu \mathrm{g} / \mathrm{L}$ at a depth of $14 \mathrm{~cm}, 6.61 \mu \mathrm{g} / \mathrm{L}$ at a depth of $14 \mathrm{~cm}$, and $20.92 \mu \mathrm{g} / \mathrm{L}$ at a depth of $11 \mathrm{~cm}$, respectively. This ensures that the phosphate in water bodies comes from biogeochemical processes that occur in sediments and is successfully measured through DGT techniques.
\end{abstract}

Keywords: DGT; oxic; phosphate release; sediment

\section{- INTRODUCTION}

Eutrophication is one of the problems of the aquatic environment caused by the emergence of excessive nutrients export from catchment soils into the water ecosystem, due to urbanization [1]. Eutrophication can cause a very rapid growth process of plants compared to their normal growth, known as blooming.

The blooming of aquatic plants such as algae can cause problems in aquatic ecosystems such as the down turn of dissolved oxygen concentration that can affect aquatic living organisms like fish and other species, causing them to not grow properly, leading to dwindling of its population. The loss of fish and other animals in the water ecosystem chain may even harm the entire ecological system [2-3]. On the other hand, there are types of algae known as cyanobacteria (blue-green algae). These algae can act as an indicator of pollution [4], in which they contain toxins that can adversely affect the health of humans and other living organisms [5-6]. Eutrophication occurs as a result of the raise of nutrients quantity in the water.

In most lakes, phosphorus is a limiting factor [7-8] in the process of algae photosynthesis because its availability is relatively insufficient compared to the number of aquatic organisms that need it. Eutrophication in inland and coastal waters is caused by increased application of nitrogen $(\mathrm{N})$ and phosphorus (P) fertilizers [9]. 
Although phosphate concentration in a water body is reduced, eutrophication can still occur due to the accumulation of large quantities of land-sourced pollutants from various sources through water flow and sediment deposition, through physical, chemical and biochemical processes [10-11]. It is clearly seen that sediment plays an important role in the availability of phosphates in the water because they act as phosphate sources and reservoirs. Therefore, the examination of phosphate distribution in sediment and how it interacts with the water body must be included in the monitoring of phosphate contamination in the water.

Organic phosphate can undergo species change into inorganic phosphate through mineralization. Organic phosphate mineralization in sediment occurs in anoxic conditions [12]. The process of phosphate mineralization in sediment causes phosphate migration from sediment to the water body. Phosphate migration from sediment is influenced by the reduction and oxidation reaction of metal iron $(\mathrm{Fe})$ ions [13].

Accurate phosphorous measurement is difficult to do because during the long sample storage, phosphorus species can change due to dynamic interactions of phosphorus species in the natural system. Therefore, in situ techniques for measuring phosphorous needs to developed. Diffusive Gradient in Thin Film (DGT) technique has been developed for in situ measurements of vanadate, arsenate, antimonate, and molybdate in water [14], methyl mercury in rice plants [15], reactive phosphorus species in natural water, sediment and soil [16] and others. The principle of phosphate measurement using the DGT technique is based on the diffusion of phosphate species through the polyacrylamide gel layer and then bound by the ferrihydrite layer embedded in the next gel layer [17]. Phosphate mass bound by ferrihydrite in a given dispersion time is measured colorimetrically after going through acid elution treatment. The concentration of analyte species bound by DGT is considered to be the same as the concentration that might diffuse into aquatic biota.

DGT is a device consisting of membrane filter, diffusive gel, and adsorbent packed in a plastic device. The diffusive gel used is an acrylamide polymer in the form of a hydrogel. In the manufacture of acrylamide polymers, DGT Crosslinker is commonly used as a crosslinker. $N, N^{\prime}$-methylenebisacrylamide can be used as a crosslinking agent in the manufacture of polyacrylamide gel [18-19].

In this study, the authors utilize the DGT technique with ferrihydrite as a binding gel and $N-N^{\prime}$ methylenebisacrylamide as a crosslinking agent for measuring phosphate released from sediment to water body in oxic condition. Measurement of released phosphate from sediment was carried out at different depths, $1-15 \mathrm{~cm}$.

\section{- EXPERIMENTAL SECTION}

The research consisted of several stages: (1) polymer synthesis and DGT sediment probe assembly, (2) sediment sampling, (3) DGT deployment in oxic condition, and (4) phosphate analysis from DGT adsorption results.

\section{Materials}

The materials used were $40 \%$ Acrylamide from Sigma Aldrich, $N, N^{\prime}$-methylenebisacrylamide from Sigma Aldrich, Ammonium persulfate from Sigma Aldrich, $N, N, N^{\prime} N^{\prime}$-Tetramethylethylenediamine (TEMED) 99\% from Sigma Aldrich, cellulose nitrate membrane filter from Whatman, Aquademineralization, $\mathrm{KH}_{2} \mathrm{PO}_{4}$, Sodium hydroxide from Merck, Sodium Nitrate/ $\mathrm{NaNO}_{3}$ (Merck), $\mathrm{H}_{2} \mathrm{SO}_{4}$ (p), Ammonium molybdate from Merck), Potassium antimonyl tartrate from Merck, Ascorbic Acid from Merck, $\mathrm{Fe}\left(\mathrm{NO}_{3}\right)_{3} \cdot 9 \mathrm{H}_{2} \mathrm{O}$ from Merck, Acetonitrile from Merck.

\section{Instrumentation}

The tools used were the Peterson Grab, ice box, $\mathrm{pH}$ meter, and thermometer QIS F-390, Portable DO meter Martini MI 605, label sticker, gloves, glassware, furnace, UV-Vis spectrophotometer Shimadzu with accuracy for phosphate analysis about 99.63-100.18\%, AAS Shimadzu 6300 with accuracy for Fe analysis about $99.63-100.18 \%$ and for $\mathrm{Mn}$ about $99.80-105.89 \%$, FTIR Bruker, Millipore water purifier, Agilent $\mathrm{pH}$ meter, Thermo science shaker, Thermo science hot plate, analytic balance, Memmert oven, Thermo science stirring hot 
plate, Iwaki glassware, DGT probe, ultrasonic, and centrifuge.

\section{Procedure}

The preparation of diffusive gel and ferrihydrite was conducted using the procedure reported by Zhang and Davison [16]. Available phosphate species was measured using a DGT technique with ferrihydrite as a diffusive gel. The gel solution was made with a composition of $15 \%$ acrylamide and $0.1 \%$ crosslinker. The crosslinker used in this study was $N, N$-methylenebisacrylamide (MBA). For binding gel, ferrihydrite was added into the gel solution. The thickness of the prepared gels was $0.23 \mathrm{~cm}$.

Sediment samples were taken from the lake of the Bogor Botanical Garden, precisely in the Lake in front of Bogor Palace at the coordinates $6^{\circ} 36^{\prime} 00.6^{\prime \prime}$ S; $106^{\circ} 47^{\prime} 51.0^{\prime \prime}$ E. The sediment were collected and filtered used a 200 mesh size filter, then stored in a reservoir. DGT probe was deployed for 7 days in oxic condition with the bubbling of oxygen. For initial data, DGT probe was deployed for $2 \mathrm{~h}$ without bubbling of oxygen. At each retrieval time, the binding gel was removed from the probe and then cut every $1 \mathrm{~cm}$. The binding gel eluted by $0.25 \mathrm{M} \mathrm{H}_{2} \mathrm{SO}_{4}$ solution and the concentration of phosphate was measured by spectrophotometer UV-Visible with blue molybdenum method. Phosphate concentration absorbed by ferrihydrite binding $\left(\mathrm{C}_{\mathrm{DGT}}\right)$ was calculated using the following formula:

$\mathrm{C}=\frac{\mathrm{M} \times \Delta_{\mathrm{g}}}{\mathrm{D} \times \mathrm{t} \times \mathrm{A}}$

where, $\mathrm{M}$ is mass of phosphate accumulated in the resin gel layer, $\Delta_{\mathrm{g}}$ is the thickness of the diffusive gel plus the thickness of the filter membrane (typically $0.123 \mathrm{~cm}$ ), D is the diffusion coefficient of phosphate in the gel $(1.63 \times$ $\left.10^{-6} \mathrm{~cm}^{2} / \mathrm{s}\right), \mathrm{t}$ is deployment time and $\mathrm{A}$ is exposure area $\left(\mathrm{A}=44.8 \mathrm{~cm}^{2}\right)$.

\section{- RESULTS AND DISCUSSION}

\section{Polymer Synthesis and DGT Probe Assembly}

DGT is a device consisting of a membrane filter, diffusive gel and binding gel, packed in a plastic device. In this study, the diffusive gel used was an acrylamide polymer in the form of a hydrogel, while the binding gel was a diffusive gel added by an adsorbent to bind with the analyte to be analyzed, and ferrihydrite was used as an adsorbent to bind with phosphate. The first step in the synthesis of the diffusive gel was the preparation of a gel solution consisting of acrylamide, crosslinker, and water.

The crosslinker used in this study was $\mathrm{N}, \mathrm{N}$ methylenebisacrylamide (MBA). After a homogeneous gel solution was formed, ammonium persulfate was added as an initiator which would trigger the occurrence of acrylamide free radical and TEMED as a catalyst. The binding gel was made in the same way as making a diffusive gel, but before adding the initiator and TEMED catalyst, ferrihydrite slurry was added first until the solution was homogeneous. The DGT probe assembly process was done as shown in Fig. 1.

This DGT device consists of a cellulose nitrate filter membrane with a pore size of $0.45 \mathrm{~nm}$. The function of this membrane filter is to filter the analyte that will enter the DGT device. The phosphate species that passes the filter with a $0.45 \mathrm{~nm}$ pore size is a dissolved phosphate species. Dissolved phosphate is divided into organic phosphate (dissolved organic phosphate, DOP) and inorganic phosphate (dissolved inorganic phosphate, DIP) [20]. Both of these species are selected in the next DGT layer, the diffusive gel layer which is an analytic diffusion medium. Phosphate species which can diffuse into this diffusive gel is inorganic phosphate (dissolved inorganic phosphate, DIP), which consists of orthophosphate and polyphosphate. This inorganic phosphate species bound by ferrihydrite binding gel is an available form and needed by plants. Phosphate concentration measured through this DGT device can be utilized to measure phosphate bioavailability.

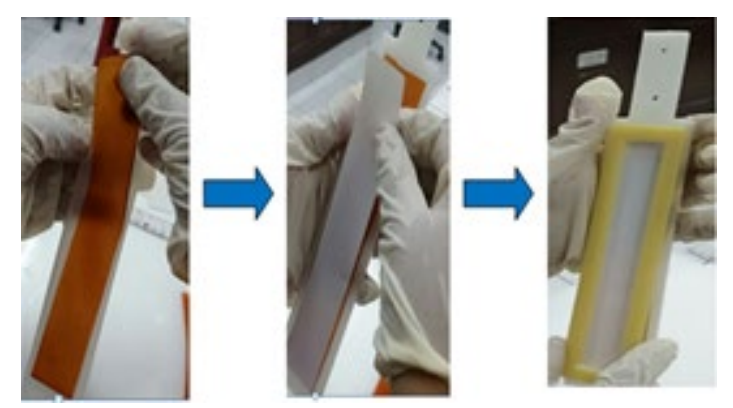

Fig 1. Sediment probe DGT assembly process 


\section{FTIR Characterization of Synthesized Polymer}

FTIR characterization was carried out to confirm that acrylamide polymer was successfully synthesized. The results of the FTIR spectrum can be seen in Fig. 2. There were two peaks at wave number of 3337 and $3188 \mathrm{~cm}^{-1}$ for the samples of diffusive gel, while for ferrihydrite gel samples, there were also two peaks at wave numbers of 3338 and $3181 \mathrm{~cm}^{-1}$. Meanwhile, typical uptake of primary amines $\left(-\mathrm{NH}_{2}\right)$ were at wave numbers of $3300-3600 \mathrm{~cm}^{-1}$ with moderate intensity form. The peak at the wave number of $1648 \mathrm{~cm}^{-1}$ for the diffusive gel sample and $1649 \mathrm{~cm}^{-1}$ for the ferrihydrite sample revealed the absorption of amide carbonyl (-CONH-), usually found at wave number of $1690-1650 \mathrm{~cm}^{-1}$ with strong intensity form. The peak at wave number of $1186 \mathrm{~cm}^{-1}$ for diffusive gel sample and $1187 \mathrm{~cm}^{-1}$ for ferrihydrite sample showed aliphatic amine uptake (C-N) usually found at wave number of $1250-1020 \mathrm{~cm}^{-1}$ with moderate intensity form. The functional group appearing was the main functional group of the acrylamide polymer, so it can be concluded that the acrylamide polymer has been successfully synthesized.

The functional group appearing in diffusive gel and binding gel were not significantly different, so it can be concluded that there is no change in polymer structure in the presence of ferrihydrite. The data also shows that the interaction between ferrihydrite and acrylamide polymer is physical interaction.

\section{Sediment Sampling and In Situ Water Analysis}

Sediment sampling was performed in the lake of the Bogor Botanical Garden, precisely in the lake in front of Bogor Palace at the coordinates $6^{\circ} 36^{\prime} 00.6^{\prime \prime}$ S; $106^{\circ} 47^{\prime} 51.0^{\prime \prime}$ E. Sediment samples were taken using a grab sampler at several adjacent points with a distance of not more than 5 meters. Measurement of some physico-chemical water parameters including temperature, $\mathrm{pH}$ and dissolved oxygen values was done simultaneously at the time of sediment collection and the results are shown in Table 1.

Lake water temperatures ranging from $28.0-30.0^{\circ} \mathrm{C}$ are considered as good enough for the growth and life of organisms in the water. Temperature is one parameter to determine the quality of lake water. Water $\mathrm{pH}$ values ranging in the interval of 7.12-7.13 indicates that the $\mathrm{pH}$

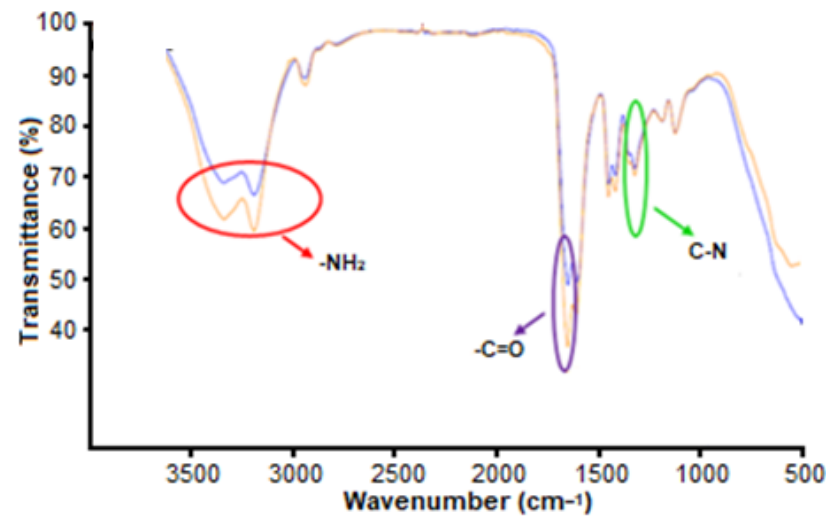

Fig 2. Spectrum FTIR $\square$ diffusive gel $\square$ ferrihydrite gel

Table 1. Measurement of temperature, $\mathrm{pH}$ and dissolved oxygen of the lake in front of Bogor Palace

\begin{tabular}{lll}
\hline No & Parameter & Result \\
\hline 1. & Temperature & $28.0-30.0{ }^{\circ} \mathrm{C}$ \\
2. & pH & $7.12-7.13$ \\
3. & Dissolved oxygen & $7.43-7.61 \mathrm{mg} / \mathrm{L}$ \\
\hline
\end{tabular}

of the water is normal. Similar to temperature, the $\mathrm{pH}$ of water can also affect the process and balance of chemical reactions that occur in the water. At a low $\mathrm{pH}$ value, dissolved oxygen content will decrease, which can directly affect the life of aquatic biota. At high $\mathrm{pH}$ values, the solubility of metal compounds decreases, followed by the development of decomposition rate, which has an impact on the decline of dissolved oxygen value [21].

DO values can show biological changes by aerobic or anaerobic organisms, therefore DO measurements are very important in monitoring water quality. The optimum value for good water conditions is when DO values are 4-6 mg/L [22]. Dissolved oxygen values ranging from 7.43 to $7.61 \mathrm{mg} / \mathrm{L}$ are still considered good. The value of dissolved oxygen is one of the parameters that can be used as an indicator of pollution. Dissolved oxygen is needed by aquatic biota for the respiratory process and metabolism, and can induce energy production for its growth and breeding process.

\section{Sediment Characterization}

In this study, sediment samples were taken from the lake and filtered using a 200 mesh size filter, then stored in a reservoir. Before the DGT was deployed, sediment characterization was conducted. Sediment 
characterization measurements were performed in 6 points with 3 different depths on the reservoir like the simulation shown in Fig. 3. The characteristics of sediment measured involved water content, Lost of Ignition, Organic $\mathrm{C}$, total $\mathrm{Mn}$, and total Fe content.

Sediment characterization was done to determine the initial conditions of the sediment before being treated. The results of the sediment characterization measurements are presented in Table 2 .

From the data in Table 2, the level of Lost of Ignition (LOI) is $20.01 \pm 0.82 \%(\mathrm{~b} / \mathrm{b})$. The LOI level was determined to see how much organic compounds are in the sediment. Fe and Mn levels were determined because both of these metals have an effect on the process of releasing phosphate from sediment to the body of water through the redox process of the two metals.

In the sediment characterization for phosphate measurements, total phosphate measurements were done, phosphate fraction from gradual extraction process was inorganic phosphate, and organic phosphate was calculated by substracting total phosphate with inorganic phosphate. The results of sediment characterization measurement are presented in Table 3.

Total phosphate determination was done with destruction process by using the persulfate method. The gradual extraction of the phosphate fraction was performed according to the method proposed by Hieltjes and Lijklema (extraction ' $\mathrm{H} \& \mathrm{~L}$ '). Based on this stepwise extraction " $\mathrm{H} \& \mathrm{~L}$ " method, the first fraction is extracted using $\mathrm{NH}_{4} \mathrm{Cl}$ solution. At this stage, the easily released phosphorus compound is extracted. The types of chemical compounds in this fraction are not clearly known yet but are thought to be orthophosphate compounds found on the surface of the water. Afterwards, the second fraction is extracted using $0.1 \mathrm{M}$ $\mathrm{NaOH}$ solution. At this stage, the phosphate compound bound by $\mathrm{Fe}(\mathrm{Fe}(\mathrm{OOH}) \approx \mathrm{P})$ is released. The third fraction is extracted using a $0.5 \mathrm{M} \mathrm{HCl}$ solution to extract phosphorus bound by calcium carbonate $\left(\mathrm{CaCO}_{3} \approx \mathrm{P}\right)$. The fourth fraction is inorganic phosphate residue. Organic phosphate levels are obtained from the difference in total P levels to the sum of the levels of each fraction [23].

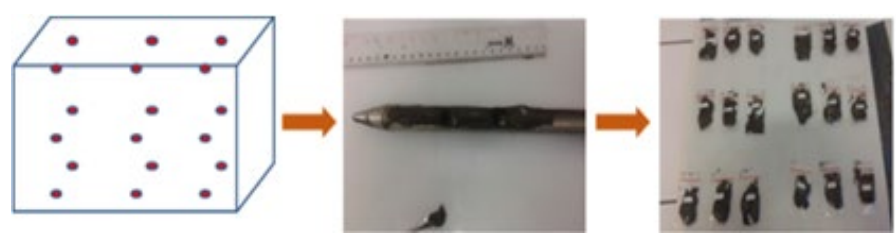

Fig 3. Sediment sampling simulation for sediment characterization

Table 2. Characterization result of sediment of Bogor Botanical Garden Lake

\begin{tabular}{lccc}
\hline \multirow{2}{*}{ Parameter Analysis } & \multicolumn{3}{c}{ Result } \\
\cline { 2 - 4 } & Top & Middle & Bottom \\
\hline Total Fe (\%) & $1.09 \pm 0.24$ & $1.14 \pm 0.22$ & $1.11 \pm 0.34$ \\
Total Mn (mg/kg) & $265.24 \pm 16.15$ & $287.12 \pm 21.74$ & $292.74 \pm 33.64$ \\
Water content (\%) & $70.53 \pm 1.00$ & $68.86 \pm 1.76$ & $66.92 \pm 1.20$ \\
LOI content (\%) & $20.28 \pm 1.96$ & $19.96 \pm 1.10$ & $20.01 \pm 0.82$ \\
Organic C (\%) & $0.57 \pm 0.26$ & $0.58 \pm 0.16$ & $0.61 \pm 0.16$ \\
\hline
\end{tabular}

Table 3. Determination of total $\mathrm{P}$ and $\mathrm{P}$ fraction level in sediment samples

\begin{tabular}{lccc}
\hline \multirow{2}{*}{ Parameter } & \multicolumn{3}{c}{ Conc. P $(\mathrm{mg} / \mathrm{kg})$} \\
\cline { 2 - 4 } & Top & Middle & Bottom \\
\hline Total P & $363.04 \pm 56.68$ & $381.40 \pm 25.20$ & $370.42 \pm 40.84$ \\
Fraction 1 & $2.27 \pm 2.04$ & $3.01 \pm 1.70$ & $1.55 \pm 0.62$ \\
Fraction 2 & $15.52 \pm 4.54$ & $13.52 \pm 2.34$ & $13.56 \pm 3.14$ \\
Fraction 3 & $0.52 \pm 0.85$ & $0.61 \pm 0.54$ & $0.62 \pm 0.48$ \\
Residual P & $1.98 \pm 8.12$ & $2.81 \pm 8.70$ & $4.34 \pm 6.78$ \\
Organic P & $342.76 \pm 60.26$ & $361.45 \pm 27.09$ & $350.36 \pm 43.60$ \\
\hline
\end{tabular}


From the data in Table 3, it is shown that the largest phosphorus fraction in the sediments of Bogor Botanical Garden Lake was organic phosphorus and the second largest fraction was phosphorus bound by Fe.

\section{DGT Deployment in Oxic Conditions}

DGT deployment in artificial sediment samples was conducted by weighing $1200 \mathrm{~g}$ of sediment into a test tube with a tube diameter of $9 \mathrm{~cm}$ and a tube height of $28 \mathrm{~cm}$. $200 \mathrm{~mL}$ of distilled water was added, then the DGT probe was placed until it touched the sediment. The spread of DGT in the sediment sample was performed in oxic condition by bubbling oxygen through an aerator flow. During the operation, dissolved oxygen values, temperature and $\mathrm{pH}$ of water on the surface of the sediment was monitored. After seven days of monitoring, we obtained some results. The temperature value range was $24.8-25.7^{\circ} \mathrm{C}$, dissolved oxygen content range was 5.91-7.91 and $\mathrm{pH}$ value range was 6.95-7.36. The deployment time was varied from day 1, 3 and 7 .

\section{Phosphate Analysis from DGT Adsorption Results}

After the specific time of deployment, the DGT probe was removed from the system and then rinsed with double distilled water. The DGT device was removed and the rollout gel was cut every $1 \mathrm{~cm}$ in height, then the phosphate level was measured by spectrophotometry method after performing the acid elution process. The phosphate absorbed into the binding gel are thought to be the phosphate which escapes from the sediment to the pore water. Data of phosphate concentration absorbed by ferrihydrite binding $\left(\mathrm{C}_{\mathrm{DGT}}\right)$ during the deployment time in oxic condition can be seen in Table 4 .

The concentration of analyte species bound by DGT is considered as similar to the concentration of analytes that may diffuse into aquatic biota, so this DGT device can be used to measure bioavailability of several analytes in the aquatic environment $[17,24]$. In this study, phosphate measurement using DGT devices was carried out to determine the phosphate concentration which might diffuse into aquatic biota.

Based on the data in Table 4, there is a tendency for $\mathrm{C}_{\mathrm{DGT}}$ to increase along with the increase in deployment time. The maximum phosphate $\mathrm{C}_{\mathrm{DGT}}$ that was obtained when the device was released on day 1 , day 3 and day 7 were $1.00 \mu \mathrm{g} / \mathrm{L}$ at a depth of $14 \mathrm{~cm}, 6.61 \mu \mathrm{g} / \mathrm{L}$ at depth of $14 \mathrm{~cm}$, and $20.92 \mu \mathrm{g} / \mathrm{L}$ at a depth of $11 \mathrm{~cm}$, respectively. The $\mathrm{C}_{\text {DGT }}$ phosphate profile absorbed by the DGT device at different depths during the deployment time is shown in Fig. 4. Based on the $\mathrm{C}_{\mathrm{DGT}}$ profile in Fig. 4, there is a tendency that as the depth increases, phosphate $\mathrm{C}_{\mathrm{DGT}}$ from the sediment decreases. This is because, as the level of sediment becomes deeper the oxygen concentration is

Table 4. Phosphate $\mathrm{C}_{\mathrm{DGT}}$ absorbed by binding gel during deployment time in oxic condition

\begin{tabular}{cccc}
\hline \multirow{2}{*}{$\begin{array}{c}\text { Depth } \\
(\mathrm{cm})\end{array}$} & \multicolumn{2}{c}{$\mathrm{C}_{\text {DGT }} \mathrm{PO}_{4}$ in oxic condition $(\mu \mathrm{g} / \mathrm{L})$} \\
\cline { 2 - 4 } & Day 1 & Day 3 & Day 7 \\
\hline 1 & $0.00 \pm 0.00$ & $1.34 \pm 1.67$ & $10.12 \pm 4.39$ \\
2 & $0.00 \pm 0.00$ & $0.00 \pm 0.00$ & $20.47 \pm 5.34$ \\
3 & $0.00 \pm 0.00$ & $3.12 \pm 5.40$ & $16.52 \pm 5.54$ \\
4 & $0.00 \pm 0.00$ & $4.79 \pm 6.27$ & $12.83 \pm 9.21$ \\
5 & $0.00 \pm 0.00$ & $0.00 \pm 0.00$ & $15.58 \pm 5.03$ \\
6 & $0.00 \pm 0.00$ & $0.00 \pm 0.00$ & $16.01 \pm 2.41$ \\
7 & $0.00 \pm 0.00$ & $0.00 \pm 0.00$ & $19.49 \pm 2.24$ \\
8 & $0.00 \pm 0.00$ & $0.56 \pm 0.96$ & $17.52 \pm 4.16$ \\
9 & $0.00 \pm 0.00$ & $5.01 \pm 8.68$ & $14.86 \pm 4.02$ \\
10 & $0.00 \pm 0.00$ & $0.22 \pm 0.39$ & $18.62 \pm 5.52$ \\
11 & $0.00 \pm 0.00$ & $6.03 \pm 5.74$ & $20.92 \pm 5.71$ \\
12 & $0.00 \pm 0.00$ & $0.00 \pm 0.00$ & $17.40 \pm 6.64$ \\
13 & $0.00 \pm 0.00$ & $0.00 \pm 0.01$ & $19.37 \pm 3.15$ \\
14 & $1.00 \pm 1.74$ & $6.61 \pm 11.45$ & $16.86 \pm 4.34$ \\
15 & $0.73 \pm 1.27$ & $0.42 \pm 0.73$ & $17.78 \pm 3.88$ \\
\hline
\end{tabular}

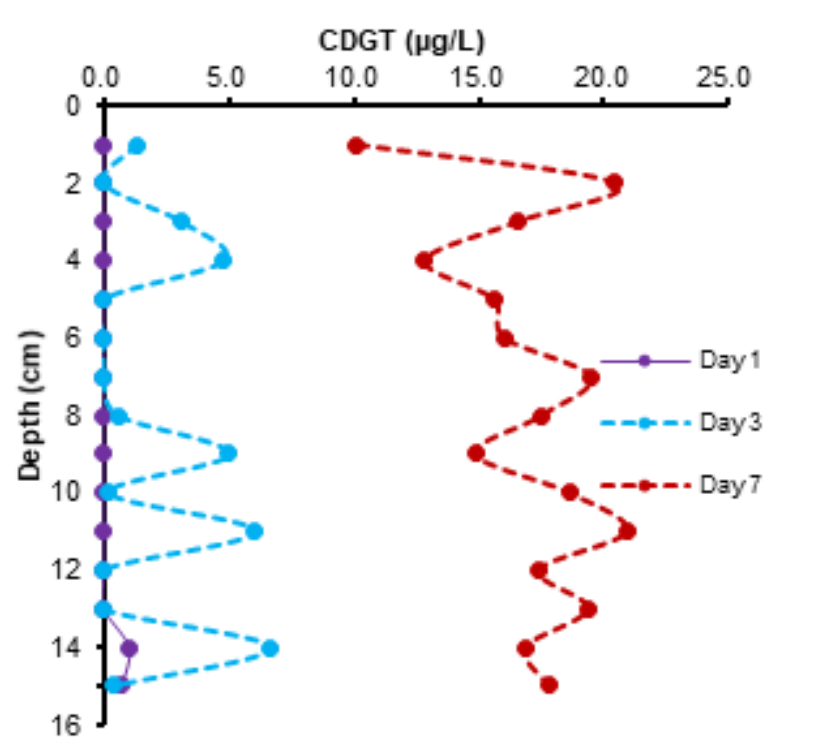

Fig 4. $C_{\text {DGT }}$ Phosphate profile for 1 day, 3 days and 7 days 
decreased so that the sediment is in anoxic condition. On the sediment interface layer with a water body, the oxygen level will be higher due to the diffusion process between water and free air. The surface layer exposed to sunlight allows photosynthesis to produce oxygen. With the increase of the depth, the dissolved oxygen level became smaller, caused by the decreasing sunlight intensity that penetrates to the water which leads to photosynthesis inhibition. In addition, the availability of oxygen used for respiratory by water organisms and the oxidation of organic and inorganic materials is limited.

When phosphate in the water body is excessive, it can be deposited back into the sediment through various ways including precipitation, adsorption, and microbial activity [1]. In anoxic condition, sediment will release phosphate bound by iron hydroxide which causes the increase of phosphate level in the water. Where as in oxic condition, the presence of iron(III) will bind with phosphate, resulting in phosphate deposition in the sediment [25]. This causes phosphate concentrations at the anoxic condition to be higher than in oxic condition. In addition, in anoxic condition, phosphorus bound by the organic phase is released from microbial activity during degradation of organic matter [26]. This ensures that the phosphate in pore water comes from biogeochemical processes that occur in sediments.

\section{- CONCLUSION}

Acrylamide polymers have been successfully synthesized with the composition of $15 \%$ acrylamide; $0.1 \% N, N^{\prime}$-methylenebisacrylamide and ferrihydrite as a binding gel. The DGT probe assembly was carried out using $16 \times 3.2 \mathrm{~cm}$ polyacrylamide gel sheets assembled on DGT probes with bindings facing upwards, followed by placing diffusive gel and filter membrane. The results of characterization of the lake sediment in Bogor Botanical Gardens at coordinates $6^{\circ} 36^{\prime} 00.6$ "S; $106^{\circ} 47^{\prime} 51.0$ "E showed that the largest phosphorus fraction in the sediments of the Bogor Botanical Garden Lake was organic phosphorus and the second largest fraction was the phosphorus bound by Fe. The result of DGT spread in sediments for 1, 3 and 7 days in oxic conditions with dissolved oxygen content about 5.91-7.91, revealed that the release of phosphate from the sediment to the water body was influenced by incubation time and depth. The released phosphate concentration tends to be higher with the increasing depth and incubation time. Maximum $\mathrm{C}_{\mathrm{DGT}}$ phosphate released on day 1, day 3 and day 7 were $1.00 \mu \mathrm{g} / \mathrm{L}$ at a depth of $14 \mathrm{~cm}, 6.61 \mu \mathrm{g} / \mathrm{L}$ at a depth of $14 \mathrm{~cm}$, and $20.92 \mu \mathrm{g} / \mathrm{L}$ at a depth of $11 \mathrm{~cm}$, respectively. This ensures that the phosphate in pore water comes from biogeochemical processes that occur in sediments. In this work, we already showed the success of the use of DGT as a probe to examine the released phosphate from the sediment to the water body. And we believe that the examination of phosphate distribution in sediments and how it interacts with the water body must be included in the monitoring of phosphate contamination in the water.

\section{- ACKNOWLEDGMENTS}

This work was supported by Polytechnic AKA Bogor.

\section{- REFERENCES}

[1] Jenny, J.P., Normandeau, A., Francus, P., Taranu, Z.E., Gregory-Eaves, I., Lapointe, F., Jautzy, J., Ojala, A.E.K., Dorioz, J.M., Schimmelmann, A., and Zolitschka, B., 2016, Urban point sources of nutrients were the leading cause for the historical spread of hypoxia across European lakes, Proc. Natl. Acad. Sci. U.S.A., 113 (45), 12655-12660.

[2] Granéli, E., and Hansen, P.J., 2006, "Allelopathy in harmful algae: A mechanism to compete for resources?" in Ecology of Harmful Algae, Vol. 189, Eds. Granéli, E., and Turner, J.T., Springer-Verlag Berlin Heidelberg, 189-201.

[3] Paerl, H.W., and Paul, W.J., 2012, Climate change: Links to the global expansion of harmful cyanobacterial, Water Res., 46 (5), 1349-1363.

[4] Kozak, A., Celewicz-Gołdyn, S., and KuczyńskaKippen, N., 2019, Cyanobacteria in small water bodies: The effect of habitat and catchment area conditions, Sci. Total Environ., 646, 1578-1587.

[5] Glibert, P.M., and Burkholder, J.M., 2011, Harmful algal blooms and eutrophication: "Strategies" for 
nutrient uptake and growth outside the Redfield comfort zone, Chin. J. Oceanol. Limnol., 29 (4), 724738.

[6] Krajewska, M., Szymczak-Żyła, M., Kobos, J., Witak, M., and Kowaleska, G., 2019, Canthaxanthin in recent sediments as an indicator of heterocystous cyanobacteria in coastal waters, Oceanologia, 61 (1), 78-88.

[7] Haas, M., Baumann, F., Castella, D., Haghipour, N., Reusch, A., Strasser, M., Eglinton, T.I., and Dubois, N., 2019, Roman-driven cultural eutrophication of Lake Murten, Switzerland, Earth Planet. Sci. Lett., 505, 110-117

[8] Burns, E.E., Comber, S., Blake. W., Goddard, R., and Couldrick, L., 2015, Determining riverine sediment storage mechanisms of biologically reactive phosphorus in situ using DGT, Environ. Sci. Pollut. Res., 22 (13), 9816-9828.

[9] Huang, J., Xu, C., Ridoutt, B.G., Wang, X., and Ren, P., 2017, Nitrogen and phosphorus losses and eutrophication potential associated with fertilizer application to cropland in China, J. Cleaner Prod., 159, 171-179.

[10] Guan, Y.F., Wang, J.Z., Ni, H.G., and Zeng, E.Y., 2009, Organochlorine pesticides and polychlorinated biphenyls in the riverine runoff of the Pearl River Delta, China: Assessment of mass loading, input source, and environmental fate, Environ. Pollut., 157 (2), 618-624.

[11] Gopal, V., Shanmugasundaram, A., Nithya, B., Magesh, N.S., and Jayaprakash, M., 2018, Water quality of the Uppanar estuary, Southern India: Implications on the level of dissolved nutrients and trace elements, Mar. Pollut. Bull., 130, 279-286.

[12] Rumhayati, B., 2010, Studi senyawa fosfat dalam sedimen dan air menggunakan teknik diffusive gradient in thin films (DGT), JID, 11 (2), 160-166.

[13] Baken, S., Verbeeck, M., Verheyen, D., Diels, J., and Smolders, E., 2015, Phosphorus losses from agricultural land to natural waters are reduced by immobilization in iron-rich sediments of drainage ditches, Water Res., 71, 160-170.
[14] Zhang, S., Williams, P.N., Zhou, C.Y., Ma, L.Q., and Luo, J., 2017, Extending the functionality of the slurry ferrihydrite-DGT method: Performance evaluation for the measurement of vanadate, arsenate, antimonate, and molybdate in water, Chemosphere, 184, 812-819.

[15] Liu, J., Feng, X., Qiu, G., Anderson, C.W., and Yao, H., 2012, Prediction of methyl mercury uptake by rice plants (Oryza sativa L.) using the diffusive gradient in thin films technique, Environ. Sci. Technol., 46 (20), 11013-11020.

[16] Zhang, C., Ding, S., Xu, D., Tang, Y., and Wong, M.H., 2014, Bioavailability assessment of phosphorus and metals in soils and sediments: A review of diffusive gradients in thin films (DGT), Environ. Monit. Assess., 186 (11), 7367-7378.

[17] Davison, W., and Zhang, H., 2012, Progress in understanding the use of diffusive gradients in thin films (DGT) - back to basics, Environ. Chem., 9, 113.

[18] Zhang, H., 2003, DGT for Measurements in Waters, Soils and Sediments, DGT Research Ltd., Lancaster, http://www.dgtresearch.com/WebProducts.aspx?C ATID=TEC, accessed on 12 December 2019.

[19] Saefumillah, A., and Rahmaniarti, R., 2015, Pengembangan metode DGT (diffusive gradients in thin film) dengan binding gel Fe-Al-Oksida dan pengikat silang $N, N^{\prime}$-methylenebisacrylamide untuk penyerapan fosfat dalam air, Valensi, 1 (1), 20-15.

[20] Zorn, M.E., Waples, J.T., Valenta, T., Kennedy, J.A., and Klump, J.V., 2018, In situ, high resolution time series of dissolved phosphate in Green Bay, Lake Michigan, J. Great Lakes Res., 44 (5), 875-882.

[21] Jiang, L., Li, Y., Zhao, X., Tillotson, M.R., Wang, W., Zhang, S., Sarpong, L., Asmaa, Q., and Pan, B., 2018, Parameter uncertainty and sensitivity analysis of the water quality model in Lake Taihu, China, Ecol. Model., 375, 1-12.

[22] Şener, S., Şener, E., and Davraz, A., 2017, Evaluation of water quality using water quality index (WQI) method and GIS in Aksu River (SW-Turkey), Sci. Total Environ, 584-585, 131-144. 
[23] Pelcová, P., Dočekalová, H., and Kleckerová, A., 2015, Determination of mercury species by the diffusive gradient in thin film technique and liquid chromatography - atomic fluorescence spectrometry after microwave extraction, Anal. Chim. Acta, 866, 21-26.

[24] Ding, S., Wang, Y., Zhang, L., Xu, L., Gong, M., and Zhang, C., 2016, New holder configurations for use in the diffusive gradients in thin films (DGT) technique, RSC Adv., 6 (91), 88143-88156.

[25] Ekholm, P., and Lehtoranta, J., 2012, Does control of soil erosion inhibit eutrophication?, J. Environ. Manage., 93 (1), 140-146.

[26] Ni, Z., Wang, S., Zhang, B.T., Wang, Y., and Li, H., 2019, Response of sediment organic phosphorus composition to lake trophic status in China, Sci. Total. Environ., 652, 495-504. 